\title{
THE UNIVERSITY ON LINE
}

\author{
Stefania Capogna \\ (Research fellowship) University “Roma Tre”, Italy
}

\begin{abstract}
The essay presents the incorporation process in the reconstruction of distance education in Italy. The paper tries to highlight the transition from modern to postmodern society, focusing both on this extraordinary change in the landscape of cultural and communication processes, and outcomes for the education system and educational and pedagogical models that govern this relationship.

The research aims to understand, on the one hand, the potential of these techno-social environments for educational systems, and on the other, raises new questions for a sociological reflection more attentive to new social dynamics produced by these technologies.

We seek to trace the effects triggered by the advent of ICT on persons and learning systems.

We starts from the idea that, despite widespread criticism, immobility of education system and the absence of an overview about the use of these new devices in teaching practices, we register a significant tendency towards change.

On the basis of these considerations, the research attempts to:

- highlight any differences in perspectives/models in use among the elearning systems and teaching practices;

- draw a reflection of risks/opportunities, strengths and weaknesses associated with the use of such instruments/techno-social environment in educational processes.
\end{abstract}

Keywords: Sociology of Education, e-learning, University, school, education, Internet, technology

\section{Introduction}

With the transition from modern to postmodern society there is an extraordinary change in the landscape of cultural and communicative processes, with clear outcomes for the educational system and pedagogical models. These processes, thanks to the development of modern communication technologies, more and more versatile, inexpensive and easy 
to use, have been incorporated by systems of distance learning.

The essay is an extract of a theoretical and empirical reflection (Capogna, 2014) organized around three themes of wich we offer a partial syntesis in this essay:

a) the evolution of Information Communication Technology;

b) the evolution of pedagogical theories;

c) the recognition of the experiences of e-learning in educational system.

\section{Information versus communication}

With regard to the changes which have affected the communication system in recent decades, we can observe a paradigm transformation from a concept of communication conceived as "information" to another considered as "participation". In fact, communication is the essential medium for any form of relationship; basic for any learning experience, and inextricably linked to the developments introduced by new telecommunication technologies. Then, the communication appears as a multidimensional and polysemic concept. It can be studied from different perspectives with various semantic variations (Boccia Artieri, 2012; Mc Luhan, 1989; Mc Quail, 1983; Ong, 1986; Wolf, 1985).

Today, there is a widely shared opinion about the evolution of ict and enhancement of communication as a social space. These relevant changes have had an impact on the evolution of distance learning, so the most significant theories of learning have been incorporated in this separation process that characterizes the learning transfered in the absence of teachers. We may recognize different theoretical approaches to learning, and different seasons of the evolution of distance learning, due to the progress of ict. Today, we are in a phase of in-depth review but only overcoming ideological and sectoral position we can reach a cross-fertilization result ${ }^{1}$.

Through a brief reconstruction based on secondary data ${ }^{2}$, we try to sketch a picture of various experiences spread in italy. On this theme, among the delays with which the italian educational system compares, at different levels, there are the informative dimension, at local level, and the resulting lack of knowledge or vision system. This produces a lack of links between center and periphery, with negative outcomes also on processes of decision making that accompany each debate on the education system.

\section{Learnining environments}

\footnotetext{
${ }^{1}$ The essay is part of a wider research study where it is possible to verify the ICT diffusion in the Italian school system and teaching practices based on ICT instruments (Capogna, 2013).

2 This refers, in particular, to Anee Reports (2004, 2006, 2010), Omniacom (2006).
} 
Today, we can distinguish three main types of technologies in use in the university, open source, proprietary and free. From a cursory survey of Universities portals, we can observe a significant spread of open source elearning platforms in Italian universities.

We can also distinguish, in summary, three main approaches in the design of learning environments:

- the first one is blended to support and integrate the traditional education, to expand markets, targets and students;

- the second one, based on electronic communication, involves the construction of the course entirely in distance learning; generally it is oriented to specific groups of students (workers, adults etc.);

- the third one, is based on the model of open course wares and free diffusion. This appears like a communication strategy can have multiple purposes: to make known their areas of intervention, to do self-promotion, to attract students, to expand markets, to enhance possibilities to build networking and bridging with the broader socio-economic context.

In this type we can include massive open online courses (MOOCs) around which there is a spread debate about the sense, the value and quality of these learning instruments (Department Business Innovation Skills, 2013). But the creation of platforms, through which to connect an increasing number of learners and teachers, does not solve the problem of knowledge construction. The risk we run is to create an education market where the only goal is the certification more than the formation and its socio-cultural impact on subjects and contexts. The change triggered by ICT within education and training systems is indeed far-reaching. It stands at the intersection point between technology, education and market. Often, e-learning is considered as a way to respond to requests from market which come from a growing and articulated demand for training, posed by the knowledge society. It is also the way to incorporate, within formal education organizations (schools and universities), non-formal education organizations (government and public and private companies), and informal education organizations (media, Internet), new contents and services for learning, so, accompanying economic development and social inclusion policies.

One of the most significant problems affecting the development of old and new media in education systems, and the necessary criticalevaluative reflection that should accompany every learning context in Italy, is given by the absence of a vision system of different levels of education, and lack clear empirical data on the use of these tools in teaching practices.

\section{The Italian way to e-learning}

Although the Italian university arrived late to e-learning, since 2003 
there has been a steady growth in the supply of educational courses, supported by e-learning systems. Italian universities that provide training courses organized based on e-learning systems increased from 24 to 45 out of a total of $77(58,4 \%)^{3}$. In 2006 six new telematic universities were established bringing the total to 11 .

Often we find dedicated centers or facilities, although not all universities devote full visibility to this training method, which is not always readily available on the home page of the University. This shows a certain weakness in the universities policies regarding abilities and strategies to adopt an integrated communication plan that can enhance and present the learning environment chosen.

In just two years, we registered a strong increase in the offer of Degree Courses in Distance learning. There has been a proliferation in the number of students who choose to study in an e-learning environment. They have passed from 9.376 a.y. 2006-2007 to 19.463 in on-line universities, and from 12.918 to 35,199 in non telematic universities. The e-learning offered by telematic universities assume an increasing importance in the wider area of the university offer (CNSUV, 2010). In 2007-2008 the 11 telematic recognized universities had a total of about 14,000 members, rising to 17.000 members in 2008-2009 a.y. However, this is about 1\% of all students enrolled in the Italian universities. Only three of these universities registered in 2010 more than 2.000 members. Analysing the composition of the population enrolled in these universities, we find that, generally, these students are over 25 years of age; very often they are people with a past spent in conventional universities, or people who are already working. In total, in the academic year 2007-2008 249 undergraduate courses online were granted. On the basis of the statements on websites, about $89 \%$ of Italian universities include in their educational offer proposals for distance learning.

The spread of e-learning courses has increased compared to previous years; in fact, we move from $32 \%$ of Italian universities who used this training method in 2004 to $68,8 \%$ in 2006.

As in previous studies we have observed a significant rate of increase among universities that use distance learning (10 in 2004 and 31 in 2006).

We observe an increased of Italian universities that offer training in e-learning courses, going from $73 \%$ of the sample in 2003 to $92 \%$ of the sample of 2006. A growing number of universities that have structured whole online degree programs courses, turning to a particular target (working students, disabled, etc.). This is especially true in the field related to education sciences, engineering and social sciences. This data is also

\footnotetext{
${ }^{3}$ Observatory Aitech-Assinform, 2006.
} 
confirmed by research ELUE according to which e-learning initiatives conducted by Italian universities are concentrated in the areas of humanities (25\%), engineering (23\%) and social sciences (18\%) (ELUE 2006). Despite an appearance of immobility and a lot of criticism, not always well-founded, this short examination shows the significant turmoil that exists in the Italian universities, on which, now, we will try to reflect focusing on the type of experiments and opportunities, projections and risks that we can view. In reference to the diversity of perspectives and models in use, we can observe different realities. We can recognize a spreading of hybrid models which use distance learning systems in various ways. Very often, they tend to use technology as a vehicle for transmission of learning content characterized by lack of multimedia connotation. This should not be considered completely negative, because it also responds to the need to promote access and inclusion of subjects with technological, cognitive emotional and use digital divide (Dijk, 2006, 2011). The first model aims to organize the on-line learning environment geared to replicate symbolic spaces that represent the places of knowledge, to accompany the insertion of the new entry activating resources gained in experiential education. The second one winds around the role of actors involved in the training program. In this case, the emphasis is on the relationship between parties involved and different areas of interaction. The first model enables the routines of knowledge, while the second stimulates most creative and subjective dimensions. The proliferation of courses, tests and telematic universities, suggests to consider the transition from the traditional model of universities, that incorporate the process of building and transmission of knowledge within rigidly determined borders and paths, in what is called multiversit@s, which gives rise to a multiplication and differentiation of opportunities for students and teachers. But the multiplication of universities, courses and opportunities may not result in the risk of de-skilling of knowledge, nor of its certifications, especially in a country where (and as long as) the regulatory framework recognizes the legal validity of titles of study.

\section{Risks and opportunities of on line learning platform}

To operate a reflection based on the logic of a Swot Analysis, we offer a summary of risks and opportunities, strengths and weaknesses, observed in educational processes with the use of these instruments and techno-social environments.

Among the strengths we can include: the liveliness of experimentations we register at bottom-up level; the diversity of models and theoretical approaches which correspond to a variety of implementative solutions; the advanced state of experimentation that allows us to operate critical reflections and evaluation actions; the speed of information and 
communication and the opportunity to capitalize the knowledge; the greater attention to the quality standards of process and products; the skepticism between a certain part of the teaching staff.

With regard to weaknesses we can mention: the chronic shortage of economic, human, professional, structural and technological resources; the shortage of clear e-learning policies; the absence of a copy right policy; the lack of educational and methodological skills for the development of ICT in teaching; spontaneity of initiatives unable to run critical mass and promote learning organization.

Regarding the opportunities we can indicate: the progressive lowering of costs in relation to the diffusion of ICT and technological infrastructures; the presence of diversified technology partners; the increasing ease in the use of technology; the variety of ways of teaching made possible by the old and new media panel; the openness to the global market; the variety of opportunities.

Finally, for a reflection on risks we have to mention: the absence of vision and policies of development at the decision making level; the lack of public investment in this segment; the inadequate technological infrastructure support in our country (Caio, 2009); a certain lack of research on these issues; a significant delay in terms of international comparisons in the field of e-learning; a considerable national delay in the ICT sector in the development of products, management software and contents marked by culture, creativity and Italian design.

\section{Conclusion}

It is now time to ask what role education systems can and should play in view of the fact that they can no longer be separated from a critical confrontation with the new social reality. However, it remains a strong conviction that no effort may be sufficient if we do not mature, at policy level, a vision of system on what could be the contribution of this sector in the overall framework of national development. But, at the same time we need to advance a management awareness of the importance of e-learning development in every organizational contexts. This is the first step to capitalize isolated experiences and produce a real change in a logic of learning organization and quality assurance. However, as we have also tried to show in the research work, of which this essay is only an excerpt, any uncritical acceptance must be repudiated. The form in which it is spreading the use of old and new media in education can not be passively accepted. Agreeing with Clegg, Hudson and Steel (2003), here it is argued the need to counter both the technological determinism as the uncritical acceptance of a neo-liberal vision of technological globalization. Technologies are never neutral but are always a concrete product and outcome of the historical and 
social relations and, as such, the embodiment of power relations and technique capabilities emerging that derived from it. ICT, being manufactured, is the result of complex social processes, which are never free from the risk of gender differences and accumulation strategies of their manufacturers and suppliers. Even looking at the way in which e-learning has developed in the university we can not avoid the fact that this has occurred, for the most part, under a managerialist fashion, sometimes more oriented to a 'save' or 'invest' objective rather than teaching

\section{References:}

Anee. Rapporto Assinform. 2004, Assinform, 2004.

Anee. Rapporto Assinform. 2006, Assinform, 2006. http://www.rapportoassinform.it/default.asp?ln=3\&Anno=2006

Anee. Rapporto Assinform, 2010: 41 anni di innovazione tecnologica in Italia, 2010. http://www.rapportoassinform.it/default.asp?ln=3\&Anno=2010 Boccia Artieri G. Web e New Media. Sociologia dei processi culturali. Franco Angeli, Milano, 2012.

Caio F. Portare l'Italia verso la leadership europea nella banda larga, 2009. Considerazioni sulle opzioni di politica industriale (Rapporto non pubblicato). 12.03.2009.

Capogna S. E-learning: Università e Scuola. Un'analisi sociologica, Armando, 2014.

Clegg S., A., Steel J. "The Emperor's New Clothes: Globalisation and elearning in Higher Education", in British Journal of Sociology of Education, vol. 4, n. 1, pp. Feb. 2003, pp. 39-53.

CNVSU. Analisi della situazione delle Università Telematiche, 2010. http://www.cnvsu.it/_library/downloadfile.asp?id=11682

Department for Business Innovation Skills, The Maturing of the MOOC. Big Research Paper N. 130, september 2013.

Dijk J. The network society. Sage Publication L.td, London (II edition), 2006.

Dijk J. A framework for digital divide research, 2011: http://www.utwente.nl/gw/vandijk/research/digital_divide/Digital_Divide_ov erigen/a_framework_for_digital_divide.doc/

Elue. L'Università verso l'e-larning: Italia, Francia, Finlandia a confronto. Progetto ELUE, 2006.

Mc Luhan M. The Global Village. Oxford University Press, Oxford, 1989.

Mc Quail D. Mass Communication Theory. An Introduction, Sage Publications Ltd, Beverly, 1983.

Omniacom. Rapporto Omniacom. http://www.wbt.it/index.php?pagina=139, 2006.

Ong W. I. Oralità e scrittura. Le tecnologie della parola. Il Mulino, 
Bologna. 1986.

Wolf M. Teorie delle comunicazioni di massa. Bompiani, Milano, 1985. 